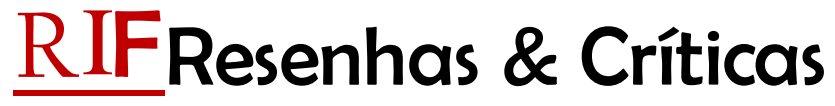

DOI - 10.5212/RIF.v.19.i43.0020

\section{Representação das lendas folclóricas pelos meios de comunicação de massa: uma análise sobre a série Cidade Invisivel, da Netflix}

Adriele Silva ${ }^{1}$

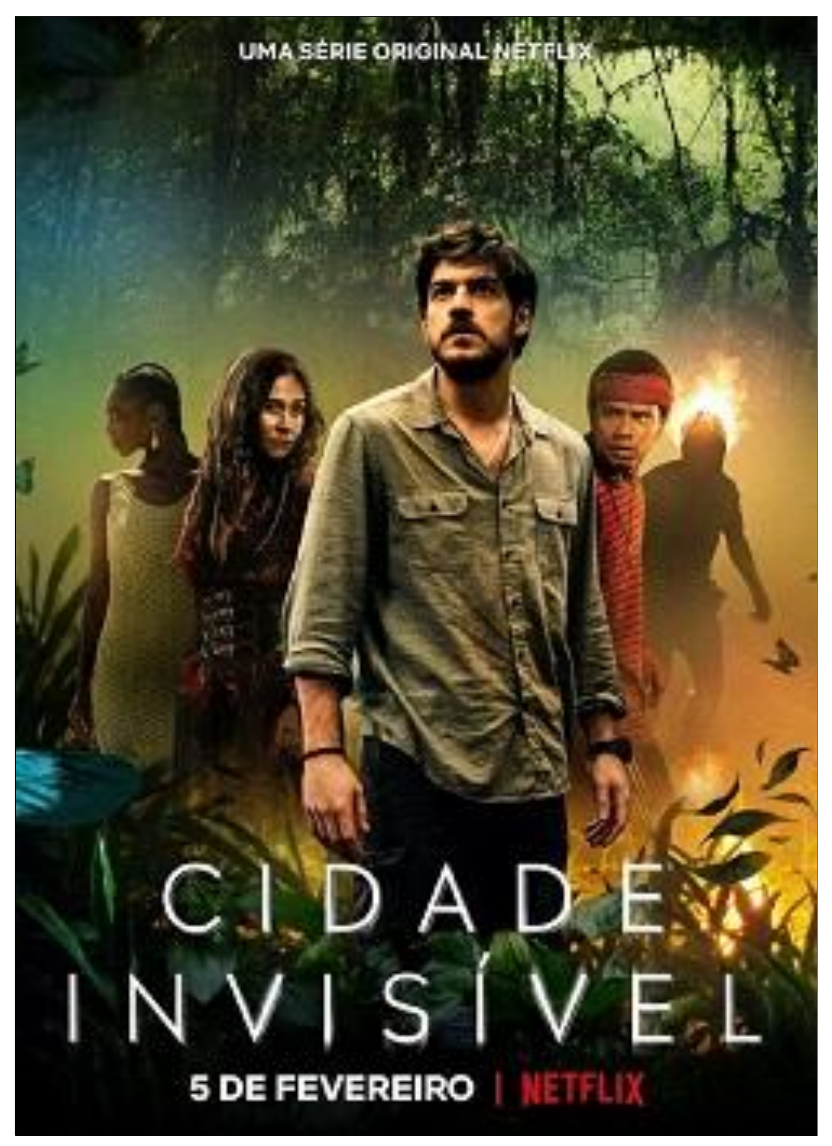

Apesar de sua extensa trajetória, que remonta à criação das Cartas do Folclore Brasileiro e culmina em obras contemporâneas que se relacionam com a cultura popular, o folclore brasileiro é comumente lembrado no país somente por suas representações infantojuvenis nos meios de comunicação de massa, tais como a série "Sítio do Picapau Amarelo", transmitida pela Rede Globo, e o programa televisivo "Catalendas", produzido pela TV Cultura.

\footnotetext{
${ }^{1}$ Jornalista, mestranda no Programa de Pós-Graduação em Jornalismo da Universidade Estadual de Ponta Grossa (UEPG). Correio eletrônico: adrie-lejose@hotmail.com.
} 


\section{RIF, Ponta Grossa/ PR Volume 19, Número 43, p.351-356, jul./dez. 2021}

O folclore, que ganhou diferentes definições ao longo do tempo, já foi compreendido como sinônimo de cultura popular, mais especificamente como um conjunto de criações culturais de um povo (CARTA DO FOLCLORE BRASILEIRO, 1995, p. 1). Hoje, o folclore, assim como a cultura popular, não sãovistos de forma engessada e vão desde lendas, costumes e manifestações artísticas, até sotaques, cantigas e pratos típicos (PORANDUBA 06, 2018, $27 \min 22 \mathrm{~s})$.

As manifestações populares, inclusive, ganham ressignificações ao serem veiculadas nos meios de comunicação de massa e se tornam "atrativos para o exibicionismo televisivo" (TRIGUEIRO, 2005, p.4).

As constantes relações entre os elementos populares e massivos, intensificadas pela globalização, possibilitam o surgimento da hibridização cultural, em que expressões culturais de classes sociais distintas convergem e "as culturas perdem sua relação exclusiva com seu território" (CANCLINI, 1997, p.348), fazendo com que "os filmes, os vídeos e canções que narram acontecimentos de um povo sejam intercambiados com outros" (CANCLINI, 1997, p.348).

Nesse sentido, a série "Cidade Invisível", produzida pela Netflix, propõe-se a representar as lendas e mitos do folclore brasileiro através de uma roupagem totalmente hollywoodiana e vendável. A produção, que une elementos folclóricos e midiáticos, coloca em jogo o debate acerca da aprop riação das manifestações populares pelo mass media: retratar a mitologia brasileira em obras comerciais promove a valorização da cultura ou reforça estereótipos e distorce as crenças?

A obra, criada por Carlos Saldanha, estreou na Netflix no início de fevereiro de 2021 e traz a história de um policial ambiental cético que, após perder sua esposa em um incêndio na floresta, tenta descobrir quem é o autor do crime. Em meio a mistério e suspense, o protagonista segue pistas e descobre a existência de um mundo repleto de magia, poder e seres mitológicos.

A primeira temporada de "Cidade Invisível" possui sete episódios, com duração média de 30 minutos cada. O primeiro episódio, intitulado "Queria muito que você estivesse aqui", se passa na floresta do Cedro, situada na fictícia Vila Toré. Na ocasião, um homem que tenta 


\section{RIF, Ponta Grossa/ PR Volume 19, Número 43, p.351-356, jul./dez. 2021}

matar Curupira é morto pelo próprio personagem folclórico, que é caracterizado, por sua vez, pelos pés virados ao contrário e pelo fogo na cabeça.

As cenas seguintes são marcadas pela morte da esposa do policial Eric em um incêndio criminoso e pela aparição repentina de um boto morto em uma das praias do Rio de Janeiro. A transformação do animal em ser humano chama a atenção do policial, que mergulha em um mundo místico em busca de respostas para os dois assassinatos.

Ao longo do episódio também são apresentados outros personagens folclóricos e suas novas versões no mundo moderno. lara, a mãe d 'água, apare ce como Camila, uma cantora do bar de Inês. Esta, por sua vez, representa a bruxa Cuca, uma mulher misteriosa que é tida como uma espécie de "mestre" de todas as outras entidades. Tutu Marambá, irmão do BichoPapão e do Boi da Cara Preta, é representado na série como o segurança do estabelecimento de Inês. Além destas lendas, aparecem ainda Isac e Iberê, que assumem, respectivamente, as identidades de Saci-Pererê e Curupira.

Ao contrário dos livros infantis de Monteiro Lobato, por exemplo, a obra não deixa explícitos os poderes das entidades, mas dá indícios para que o público descubra no decorrer dos episódios. Camila, por exemplo, tem sua identidade revelada ao atrair Eric com sua voz. Inês, por sua vez, tem seu poder atrelado às poções e artigos mágicos em seu bar. Tutu, que ganha a forma de um porco-do-mato ao longo da série, é desvendado pelo público por causa de seu olfato apurado. Iberê, por sua vez, aparece em uma cadeira de rodas com seus pés cobertos, enquanto Isac traz uma bandana vermelha em analogia ao gorro do Saci.

No segundo capítulo, "é um caminho sem volta", uma sucessão de acontecimentos leva o policial a descobrir que o boto era conhecido na forma humana como Manaus, um rapaz que frequentava as festas e bares da Vila Toré e que mantinha relacionamentos com as mulheres do local.

Seguindo as descrições das mitologias indígenas, a série retrata Manaus como um homem branco, elegante e galanteador (CASCUDO, 2012, p. 182). Apesar disso, a romantização do personagem pode reforçar a naturalização da violência de gênero e dos abusos sexuais, uma vez que, na mitologia, o boto costumava forçar as índias a "entregaremse" para ele (CASCUDO, 2012, p. 182). 


\section{RIF, Ponta Grossa/ PR Volume 19, Número 43, p.351-356, jul./dez. 2021}

Ao longo do episódio, Inês percebe que alguma força mágica deseja acabar com todas as lendas que restam. A fala, inclusive, pode ser considerada uma referência à crescente desvalorização dos saberes folclóricos no país, bem como o esquecimento seletivo de elementos ligados à identidade nacional.

A bruxa culpa Eric pelo assassinato de Manaus e inicia uma batalha para matá-lo. No episódio "eles estão entre nós" é revelado que Camila se transformou em uma entidade após ser vítima de feminicídio. A versão, entretanto, diverge dos estudos de Cascudo, que atribui a sua origem às tradições dos gregos e portugueses (CASCUDO, 2012, p. 447).

No episódio 4, "a Cuca vai pegar", o público descobre a existência de um novo mito folclórico: o Corpo Seco. Segundo a lenda, se trata de um homem mau que, ao morrer, "nem Deus nem o Diabo o quiseram. E, um dia, da tumba se levantou, para vagar e assombrar os viventes na calada da noite" (CASCUDO, 2012, p. 313). Através de flashbacks, descobre-se que o homem morto pelo Curupira no passado havia se transformado no Corpo Seco. Na época de sua morte, Inês o enterrou para que sua alma ficasse aprisionada, mas, após anos, o túmulo foi reaberto e o antagonista, liberto. Com a entidade à solta, novos assassinatos ocorrem e a corrida para descobrir o paradeiro de Corpo Se co se intensifica.

No episódio "você não vai acreditar em mim", o trauma vivido por Inês no passado e sua transformação em entidade são revelados ao público. Assim como os outros personagens, a origem da bruxa na série é fictícia, tendo em vista que o mito nasceu em Portugal e se relaciona a Santa Coca, uma figura das procissões da província de Minho. (CASCUDO, 2012, p. 325).

Os últimos episódios, intitulados de "coisa de criança" e "é muito maior que a gente", resultam em uma série de revelações que colocam fim ao mistério dos assassinatos e deixam em evidência o autor do incêndio que matou a esposa do policial. Além disso, um duelo final entre Corpo Seco e Curupira resulta na morte de uma das entidades e encerra a temporada com o nascimento de uma nova lenda folclórica.

De maneira geral, apesar de possuir licença poética para promover adaptações nas lendas folclóricas, a série apresenta várias divergências quanto às origens dos mitos. Além disso, podem ser identificadas outras duas distorções que prejudicam a compreensão real do 


\section{RIF, Ponta Grossa/ PR Volume 19, Número 43, p.351-356, jul./dez. 2021}

folclore, principalmente para aqueles que não possuem nenhum contato com a cultura brasileira, como é o caso do público dos mais de quarenta países em que a série foi exibida.

A primeira inconsistência aparece na escolha do Rio de Janeiro para ambi entar toda a trama. Apesar da cultura folclórica perpassar fronteiras e estar presente em todas as regiões brasileiras, é no Norte e no Nordeste que a mitologia finca suas raízes. O próprio Boto, conforme diz Cascudo, é um golfinho que atraia as jovens ribeirinhas para os principais afluentes do rio Amazonas (CASCUDO, 2012, p. 182). Além disso, a sereia lara, representada por Camila, também é reconhecida na mitologia por ser a mãe d'água e viver apenas em águas doces, o que não ocorre na série.

A ausência de atores e personagens indígenas configura a segunda distorção encontrada na temporada, uma vez que as lendas folclóricas são frutos de criações, apropriações e transformações de histórias de diferentes povos, tendo, portanto, uma grande contribuição da população indígena.

Ainda assim, "Cidade Invisível" coloca em evidência a necessidade da valorização da identidade brasileira e, através da hibridização cultural e da convergência de elementos populares e massivos, difunde a cultura popular mesmo que com uma roupagem midiatizada.

\section{Ficha Técnica:}

Título: Cidade Invisível

Autor:Carlos Saldanha

Direção: Júlia Pacheco Jordão e LuisCarone

Distribuição: Netflix

Ano: 2021

Duração: 30-40 minutos/episódio

Gênero: Fantasia, drama 


\section{Referências}

CANCLNI, Néstor García. Culturas híbridas: estratégias para entrar e sair da modernidade. Trad. Heloísa P. Cintrão e Ana Regina Lessa. 2.ed. São Paulo: Edusp, 1997.

CASCUDO, Luís da Câmara. Dicionário do Folclore Brasileiro. São Paulo: Global, 2012.

CASCUDO, Luís da Câmara. Literatura Oral no Brasil. São Paulo: EdUSP, 1984.

COSTA, Andriolli. Poranduba 06 - Conceitos 2018. (45m14s). Disponível em:

$<$ https://anchor.fm/poranduba/episodes/Poranduba-06---Conceitos-e8cdkd>. Acesso em: 04 jun. 2021.

COMISSÃO NACIONAL DE FOLCLORE. Releitura da Carta do Folclore Brasileiro de 1951. Boletim nำ18, edição especial com noticiário do VIII Congresso Brasileiro de Foldore. Salvador, 1995.

TRIGUEIRO, Osval do Meira. Os caminhos da folkcomunicação na atualidade: perspectivas para o século XXI. In: LOPES FILHO, Boanerges [et. al.]. A folkcomunicação no limiar do século XXI. Juiz de Fora: Ed. UFJF, 2012. 